\title{
Localized Increment and Decrement in the Total Electron Content of the Ionosphere as a Response to the April 20, 2018, Geomagnetic Storm
}

\author{
Carlos Sotomayor-Beltran (ii) \\ Image Processing Research Laboratory (INTI-Lab), Universidad de Ciencias y Humanidades, Lima 39, Peru \\ Correspondence should be addressed to Carlos Sotomayor-Beltran; csotomayor@uch.edu.pe
}

Received 20 July 2018; Revised 26 August 2018; Accepted 2 September 2018; Published 18 September 2018

Academic Editor: Angelo De Santis

Copyright (C) 2018 Carlos Sotomayor-Beltran. This is an open access article distributed under the Creative Commons Attribution License, which permits unrestricted use, distribution, and reproduction in any medium, provided the original work is properly cited.

\begin{abstract}
A moderate geomagnetic storm occurred on April 20, 2018. Using vertical total electron content (VTEC) maps provided by the Center for Orbit Determination in Europe, ionospheric responses to the geomagnetic storm could be identified in generated twodimensional differential VTEC maps. During the day of the storm the enhancement of the equatorial ionization anomaly (EIA), product of the super-fountain effect was identified. A localized TEC enhancement (LTE) was also observed to the south of the EIA on April 20, 2018. It was also possible to visualize this LTE in a longitudinal section of the EIA as a third crest. The maximum increment of VTEC for the LTE was 204\%. This LTE is quite unique because it happened during the expected solar cycle 24 and 25 minimum, and according to a previous study no LTE observation could be done for the last solar two-cycle minimum. The origin of the observed LTE is suggested to be partly product of the super-fountain effect. Finally, a localized TEC decrement (LTD) was observed towards the end of the day, April 20, 2018. Because this LTD consisted in the disappearance of the northern and southern crests of the EIA and this occurred during the recovery phase of the geomagnetic storm, it can be suggested that the LTD origin is due to the westward disturbance electric field. This mechanism was put forward by a past study that also analyzed the responses to a geomagnetic storm (the 2015 St. Patrick's day storm), being one of the responses the inhibition of both crests of the EIA.
\end{abstract}

\section{Introduction}

Geomagnetic storms can be very disruptive. For instance, they can induce currents in main electricity grids, can adversely affect global positioning system by considerably reducing its accuracy and also can cause the loss of highfrequency radio communications (e.g., [1, 2]). The ionosphere, which is a layer of the atmosphere located between $\sim 60$ and $1000 \mathrm{~km}$ in altitude, responds to geomagnetic storms in the form of ionospheric storms. Ionospheric storms can be classified as positive or negative (e.g., [3-5]), i.e., when there is an increment or decrement in the total electron density (TEC), respectively.

At low latitudes, a noticeable feature in the $F$ layer of the ionosphere is the equatorial ionization anomaly (EIA; [6]). This anomaly consists of two regions of enhanced plasma located at $\pm 15^{\circ}$ of the magnetic equator. This phenomenon is mainly due to eastward zonal electric field which in combination with the Earth's magnetic field at equatorial latitudes produces an upward $\mathbf{E} \times \mathbf{B}$ drift of the plasma. Once high altitudes are reached, the plasma diffuses along the geomagnetic field lines due to pressure gradient forces in conjunction with the action of gravity [7]. This whole process is also known as the equatorial fountain effect. On the other hand when a geomagnetic storm sets in, it has been previously observed in several studies (e.g., [8-12]) that the EIA is also considerably enhanced, which is due to the penetration of the interplanetary electric field from high to low latitudes and which lasts for several hours [13]. As a consequence of the electric field penetration, there is an upward displacement of plasma to higher altitudes and also an expansion of the EIA in the direction of the poles (e.g., [12]). In this case, this phenomenon is known as the super-fountain effect. 

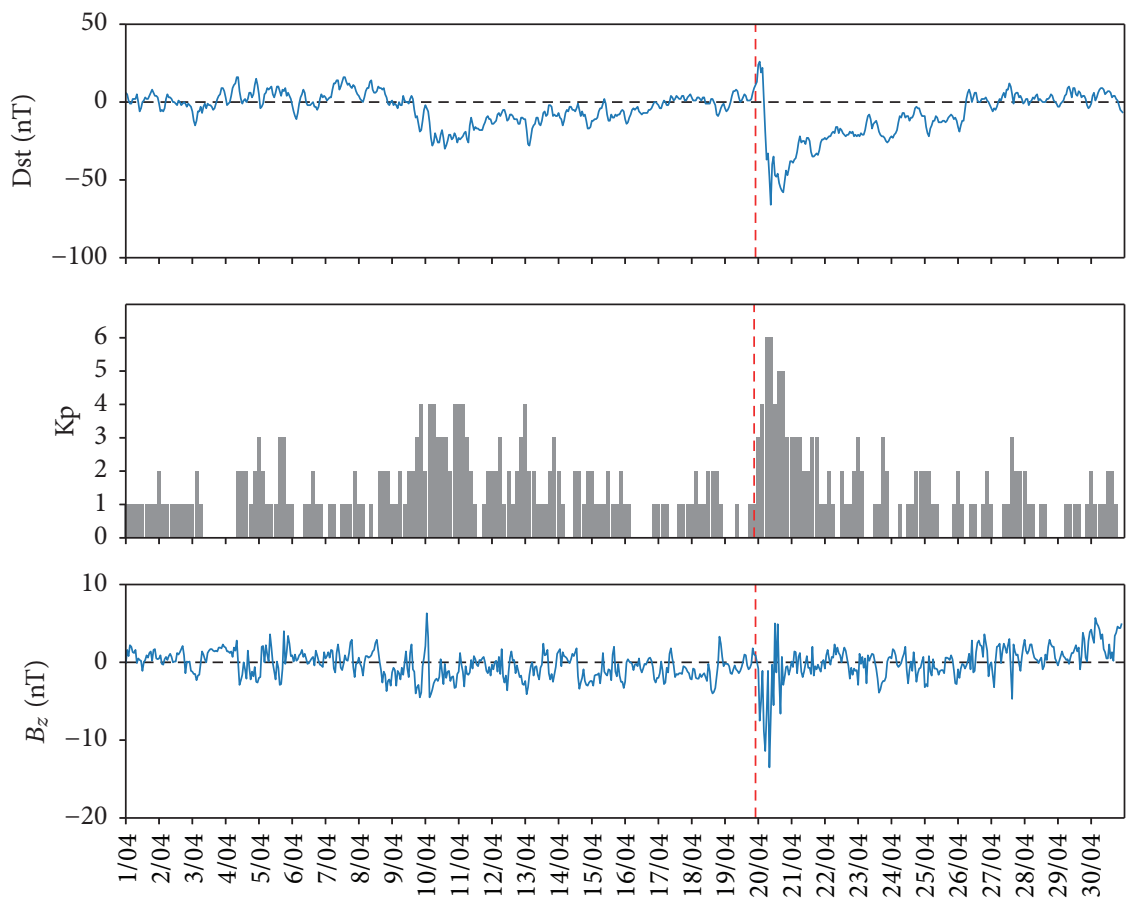

Figure 1: Dst and Kp geomagnetic indices during April 2018. Additionally, the vertical component of the interplanetary magnetic field $\left(B_{z}\right)$ is shown. The vertical red dashed line indicates the storm sudden commencement (SSC).

Besides the expected diurnal response of the EIA to geomagnetic storms in the low and midlatitude ionosphere, there are still not well-defined physical mechanisms that can account for the anomalous increase or decrease of TEC outside the extent of the EIA. Very recently, Edemskiy et al. [14] have observed that the ionospheric response to the August 15,2015 , geomagnetic storm presented not only the regular increment of TEC in the EIA, but also two regions of localized TEC enhancements (LTEs or localized positive ionospheric storms $)$ at central-middle $\left(\sim 35^{\circ} \mathrm{S}\right)$ and lower-high latitudes $\left(\sim 62^{\circ} \mathrm{S}\right)$ were identified. The aforementioned study suggested that the excursion of the vertical interplanetary magnetic field $\left(B_{z}\right)$ was necessary but not a definite requirement for the appearance of the observed LTEs.

In this paper, publicly available vertical TEC (VTEC) data from the Center for Orbit Determination in Europe (CODE) were used to investigate the ionospheric responses to the April 20, 2018, geomagnetic storm that happened during the expected time of the solar cycle 24 and 25 minimum [15].

\section{Data and Method}

2.1. Ionospheric Data. In order to detect ionospheric anomalies due to the geomagnetic storm of April 20, 2018, global maps of VTEC provided by CODE were used. As indicated by previous studies $[16,17]$, global ionospheric maps (GIMs) are good indicators of space weather events.

GIMs are routinely produced every hour and they come in daily IONosphere Map EXchange files (IONEX; [18]). CODE makes IONEX files publicly available via their $\mathrm{ftp}$ site (ftp://ftp.aiub.unibe.ch/CODE/). GIMs provide VTEC in a global geographical grid with a resolution of $5^{\circ} \times 2.5^{\circ}$ (longitude and latitude, respectively). The total number of cells in latitude is 71 and in longitude is 73. The VTEC values are given in TEC Units (TECU), where 1 TECU $=10^{16}$ electrons $/ \mathrm{m}^{2}$. The accuracy of the GIMs is between 2 to 9 TECU. Due to the bit of structural complexity of the IONEX files, a program using the library NumPy from Python was written. NumPy has the ability to work efficiently with $\mathrm{N}$ dimensional arrays [19]. The result after this preprocessing stage was to obtain 3D cubes of VTEC per each IONEX file.

Ionospheric disturbances can be properly identified from GIMs assuming that the VTEC within a certain range of days follows a Gaussian distribution (e.g., [20-23]). Under this consideration, the upper bound $(U B)$ and lower bounds $(L B)$ can be defined as $\mu+2 \sigma$ and $\mu-2 \sigma$, respectively (where $\mu$ is the mean and $\sigma$ the standard deviation). In this way, a $3 \mathrm{D}$ cube of differential VTEC ( $\triangle$ VTEC) at a confidence level of $95 \%$ was constructed based on the 3 D VTEC cubes. Positive and negative ionospheric anomalies are identified in the $3 \mathrm{D}$ $\triangle$ VTEC cube when

$$
\Delta \text { VTEC }= \begin{cases}+, & \text { if VTEC }>U B \\ 0, & \text { if } U B \geq \text { VTEC } \geq L B \\ -, & \text { if VTEC }<L B\end{cases}
$$

2.2. Geomagnetic Conditions. In Figure 1, the variability of two important geomagnetic indices, Dst and Kp, during the 

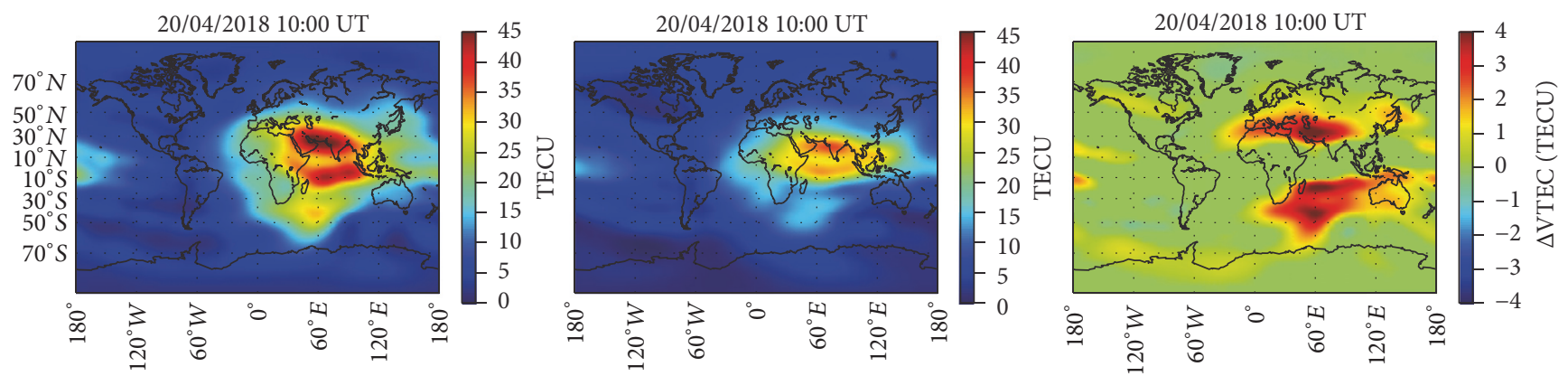

Figure 2: Left: GIM for April 20, 2018 at 10:00 UT. Center: map of the mean ( $\mu$ ) VTEC for April 20, 2018, at 10:00 UT. Right: differential VTEC map for April 20, 2018, at 10:00 UT.

month of April 2018 can be observed. While the Kp index indicates the severity of a storm, the Dst index is a proxy for the strength of westward terrestrial ring current [24]. As seen in Figure 1, the Kp index for April 20, 2018, between 06:00 and 12:00 has a value of $K p=6$, which according to the National Oceanic and Atmospheric Administration (NOAA) space weather scales points to a moderate G2 storm. On April 19, 2018, at 22:00 UT the Dst index rises to a value of $11 \mathrm{nT}$, which marks the storm sudden commencement (SSC), and it also indicates the start of the initial phase of the storm $[25,26]$. On April 20, 2018, at 05:00 UT the Dst decreased drastically to a negative value of $-19 \mathrm{nT}$. The Dst index reached its minimum of -66 nT at 09:00 UT, time in which the main phase finished. Kp and Dst data were downloaded from the German Research Center for Geosciences (https://www.gfz-potsdam.de/en/kp-index/) and the World Data Center for Geomagnetism in Kyoto (http://wdc.kugi.kyoto-u.ac.jp/wdc/Sec3.html), respectively.

In addition to the geomagnetic indices, a very crucial parameter that drives the development of a geomagnetic storm is the vertical interplanetary magnetic field $\left(B_{z}\right)$. Gonzalez and Tsurutani [27] have indicated that, for strong storms, the observed southward $B_{z}$ is lower than $-10 \mathrm{nT}$ and it remains below this threshold for at least three hours. On the other hand, Gonzalez et al. [25] pointed that, for moderate storms $(-100 \mathrm{nT}<$ Dst $\leq-50 \mathrm{nT}), B_{z} \leq-5 \mathrm{nT}$ for at least 2 hours. It is the latter what is observed during the geomagnetic storm of April 20, 2018. In the bottom plot of Figure 1, it can be observed that $B_{z} \leq-5 \mathrm{nT}$, most of the time ranging within April 20, 2018, at 01:00 until 16:00 UT. Data for $B_{z}$ in geomagnetic solar magnetospheric coordinate system was retrieved as hourly averages from the OMNI database (https://omniweb.gsfc.nasa.gov/form/dxl.html).

\section{Results and Discussion}

In order to better appreciate how maps of $\triangle$ VTEC improve the detection of ionospheric anomalies due to geomagnetic storms, Figure 2 shows a GIM (left), a map containing the mean VTEC (center), and the $\triangle$ VTEC map (right) for April 20,2018 , at 10:00 UT. It can be observed in the $\triangle$ VTEC map that the two enhanced plasma regions that form the EIA are displaced towards the poles $\left(\sim 30^{\circ} \mathrm{N}\right.$ and $\left.\sim 25^{\circ} \mathrm{S}\right)$, confirming what it was noticed for other geomagnetic storms in past studies (e.g., [8-12, 28, 29]). Furthermore in the $\triangle$ VTEC map of Figure 2, a well-defined LTE in the southern hemisphere at higher-middle latitudes $\left(\sim 44^{\circ} \mathrm{S}\right)$ can be clearly identified. The GIM is also showing this LTE; however, there is no doubt when looking at the $\triangle$ VTEC map that the LTE is properly displayed showing clearly its complete spatial distribution.

3.1. Localized TEC Enhancement. After carefully inspecting the generated $\triangle$ VTEC cube, as previously seen in Figure 2, a LTE was observed to appear on April 20, 2018, at 06:00 UT (Figure 3). The LTE appeared about 8 hours after the SSC to the south of the EIA $\left(\sim 44^{\circ} \mathrm{S}\right)$ right over the Indian Ocean. At later times the LTE started to drift westward (same as the direction of the Sun). Edemskiy et al. [14] have also observed such displacement for the two LTEs they detected during the August 15, 2015, geomagnetic storm. At $\sim 10: 00$ UT the LTE reached its maximum intensity with a $\triangle$ VTEC of 4.07 TECU. At this hour the EIA reached also its peak $\triangle$ VTEC intensity of $4.33 \mathrm{TECU}$ in the northern plasma region. As seen in Figure 3, the enhancement of the EIA lasted only for about 6 hours (08:00 until 14:00 UT), whereas the LTE is almost visible until April 21, 2018, at 00:00 UT. At this time the LTE is located over the south Pacific to finally fade away. It is worth mentioning that approximately two hours after (16:00 UT) the enhanced EIA disappears, $B_{z}$ returns to its regular variability. A day before (April 19, 2018) and after (April 21, 2018) the occurrence of the geomagnetic storm, the $\triangle$ VTEC maps for these days revealed that there was no EIA enhancement or appearance of LTEs.

In order to appreciate the shape of the EIA and the LTE, a meridional profile along the $58.5^{\circ} \mathrm{E}$ at 10:00 UT (14:00 local time for this longitudinal coordinate) is shown in Figure 4. At this time and longitudinal coordinate, which is pretty much the same for the capital city of Oman, Muscat, the LTE reached, as previously mentioned, its highest intensity. The EIA shape is also shown at the same UT for 2 days before and after the geomagnetic storm. From Figure 4 it can be noticed that, for April 18, 19,21, and 22, 2018, at 10:00 UT, the EIA shape has a well-defined double-crest with a trough form [6], which is expected during daytime 


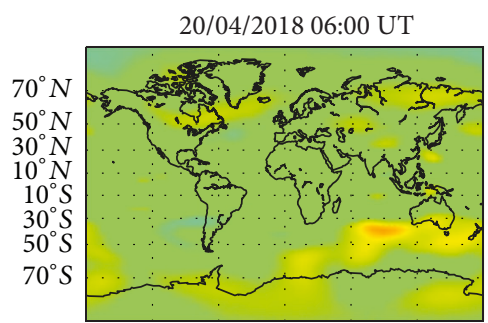

20/04/2018 10:00 UT

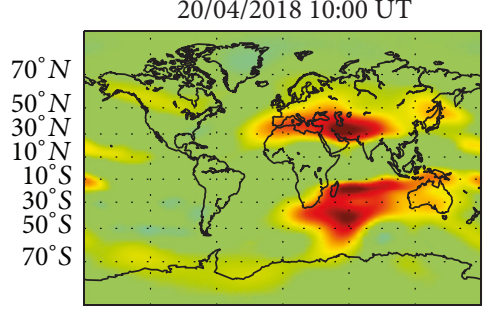

20/04/2018 14:00 UT

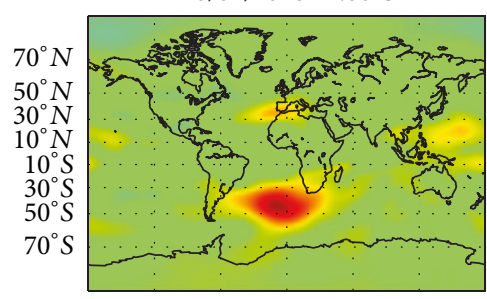

20/04/2018 18:00 UT

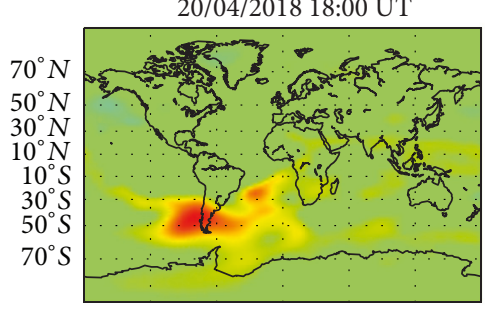

20/04/2018 22:00 UT

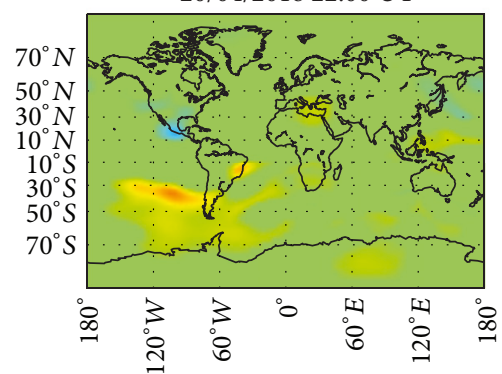

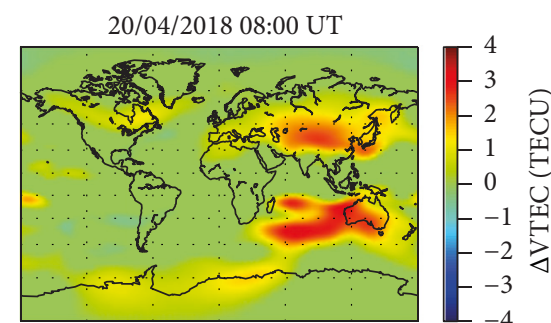

20/04/2018 12:00 UT

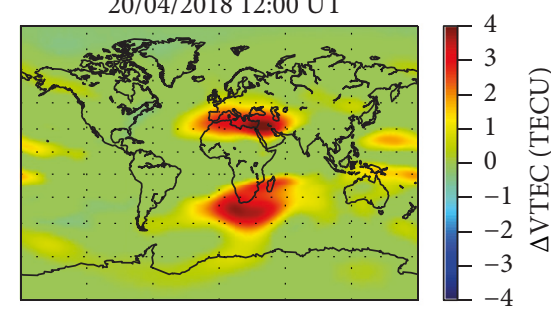

20/04/2018 16:00 UT

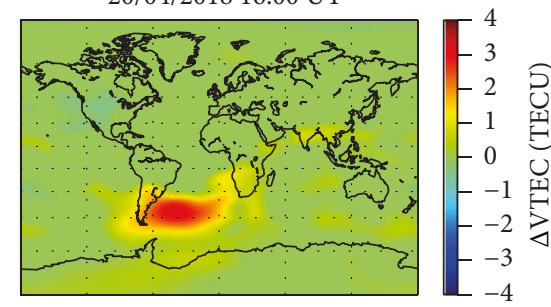

20/04/2018 20:00 UT

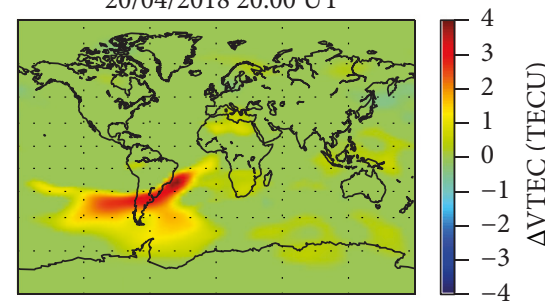

21/04/2018 00:00 UT

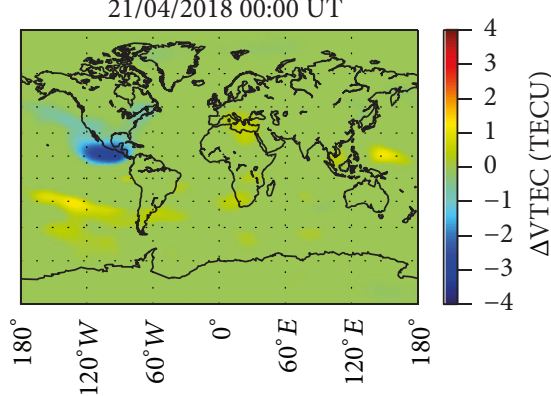

FIgURE 3: Differential VTEC maps between April 20, 2018 (06:00 UT), and April 21, 2018 (00:00 UT).

because of the equatorial fountain effect. During the day of the storm at 10:00 UT, Figure 4 also shows that the EIA is enhanced by showing a considerably increase of the VTEC in the northern hemisphere of $\sim 133 \%$ and at the same time a poleward displacement of the crests, this being product of the super-fountain effect (e.g., $[8-12,29]$ ). On the other hand, an unexpected response to the storm in the EIA shape is the additional presence of a third crest $\left(\sim 44^{\circ} \mathrm{S}\right)$, which corresponds to the LTE observed in the southern hemisphere in Figure 3. However, it can be seen that, during the days before the storm (April 18 and 19, 2018) and after (April 21 and 22, 2018), the meridional profiles show as well a slight increment of their TEC in the same position of the observed third crest, for the LTE the peak increment in VTEC is of $\sim 204 \%$. Here it could be suggested that the super-fountain effect, which is caused due to southern flip of $B_{z}$, with some other physical mechanism may be playing an important role in the generation of this LTE.

Edemskiy et al. [14] have not only detected the two LTEs observed during the geomagnetic storm of August 


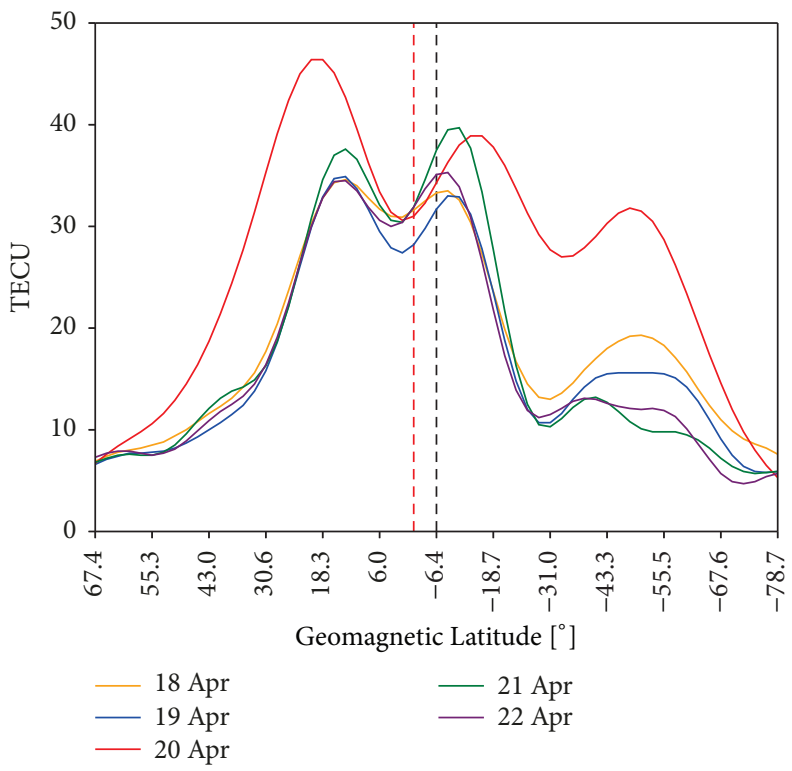

FIgURE 4: Shape of the VTEC for the $58.5^{\circ} \mathrm{E}$ meridian at 10:00 UT between April 18 and 22, 2018. A relevant range of geomagnetic latitudes is shown, $67.4^{\circ} \mathrm{N}-78.7^{\circ} \mathrm{S}\left(75^{\circ} \mathrm{N}-75^{\circ} \mathrm{S}\right.$ in geographic latitudes). The vertical red and black dashed lines indicate the magnetic equator and the equator (geographic latitude $=0^{\circ}$ ), respectively.

15, 2015, but they also discovered further 26 LTEs for the period of 2002-2015. However, they indicated that, during the time of the solar activity minimum of 2006-2009, there was no detection of LTEs. Thus in the present study, the detected LTE during the April 20, 2018, storms is the first identification of such type of event (LTE) during a solar cycle minimum. According to Hathaway and Upton [15], between 2016 and 2019 the solar cycle 24 and 25 minimum is expected.

3.2. Localized TEC Decrement. In Figure 3 at 22:00 UT on April 20, 2018, and at 00:00 UT on April 21, 2018, a negative storm or a localized TEC decrement (LTD) could be already observed. However, for completeness, the whole event is presented in Figure 5. This LTD appears at 22:00 UT on April 20, 2018, right over the southern half of Mexico. At 00:00 UT on April 21, 2018, the LTD moved to the west and reached its minimum peak intensity with a $\triangle \mathrm{VTEC}$ of -3.21 TECU. This negative storm was quite transitory; by 04:00 UT it completely disappeared. On the other hand the GIMs for this period of hours, also presented in Figure 5, show apparently that the northern plasma region of the EIA disappears, although from the GIMs alone this is not completely clear.

In order to have a better view of what is occurring with the EIA, meridional profiles for $100^{\circ} \mathrm{W}$ at 00:00 UT between April 19 and 23, 2018, are presented in Figure 6. The $100^{\circ} \mathrm{W}$ longitudinal coordinate is about the same as the one for Mexico City (capital of Mexico), where the local time is 19:00 hours. On April 19, 20, 22, and 13, 2018, at 00:00 UT (19:00 local time) the EIA shape shows a double-crest with a trough, which is still expected after sunset. However, what was unforeseen, as to what is seen in Figure 5, was the disappearance of both crests on April 21, 2018, at 00:00 UT, time when the recovery phase is already under way. The disappearance of the crests corresponds to the negative ionospheric storm observed in the $\triangle$ VTEC maps of Figure 5. In Figure 6 it can be seen that the peak of the meridional profile for April 21, 2018, at 00:00 UT falls nearly in the location of the magnetic equator. A similar situation, where the northern and southern crests faded away, happened during the 2015 St. Patrick's Day storm on March 18, 2015, at the beginning of the recovery phase [30]. In the aforementioned study it was indicated that the westward disturbance electric field is the most likely mechanism that could inhibit the formation of both crests. Thus it can be suggested that the same process is causing the disappearance of both crests observed for the April 20, 2018 storm during the recovery phase.

\section{Conclusions}

Analysis of differential VTEC content maps during the G2 (moderate) geomagnetic storm that occurred on April 20, 2018, has revealed different ionospheric responses. The expected response to the super-fountain effect was observed for a period of 6 hours with a maximum increment of VTEC of $133 \%$ in the northern crest of the equatorial ionization anomaly.

A localized TEC enhancement has also been observed during the storm, located to the south of the EIA. The maximum increment of VTEC for the LTE is of 204\%. This LTE appeared two hours before the EIA was enhanced and also lasted until nearly the end of the day. The LTE shows itself as a third crest in the longitudinal profile of the EIA. 

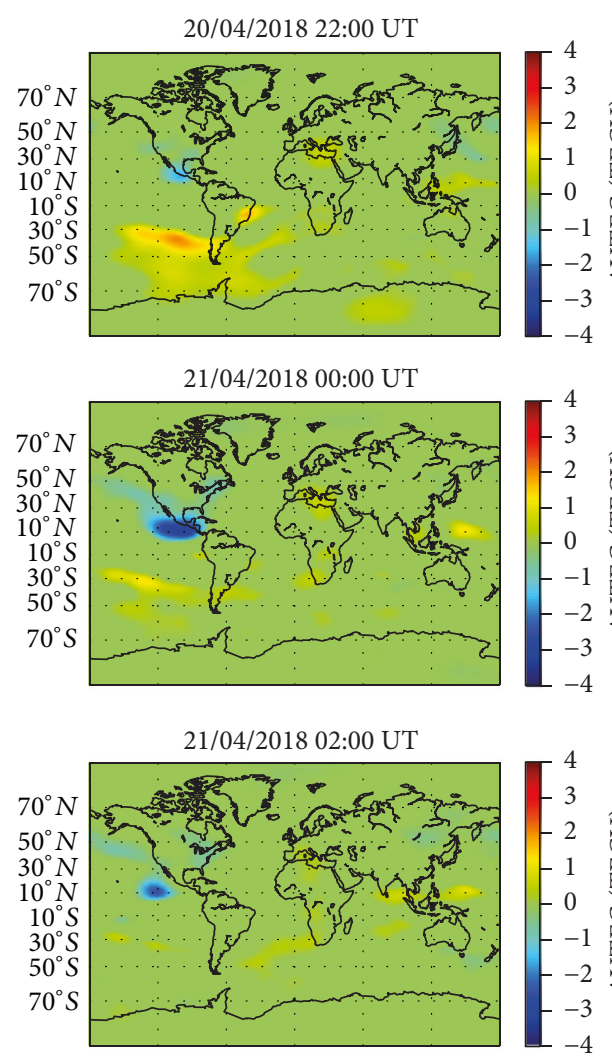

21/04/2018 04:00 UT

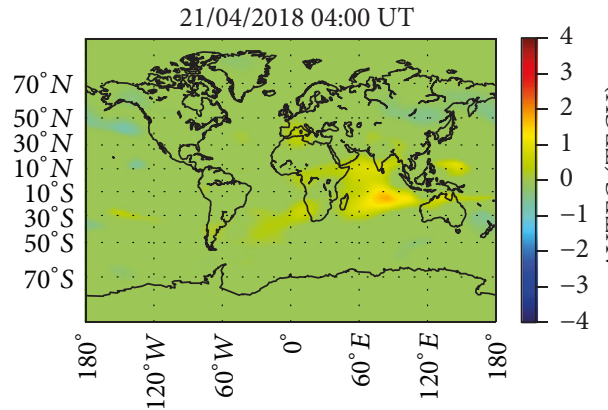

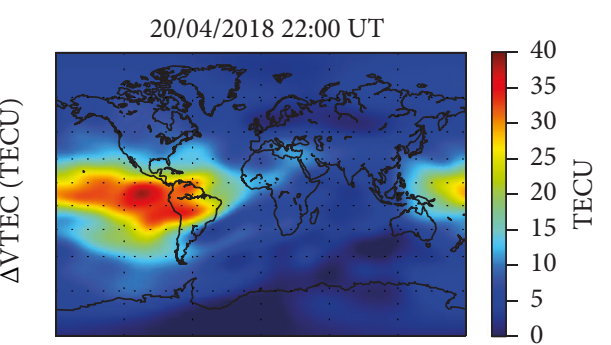

21/04/2018 00:00 UT

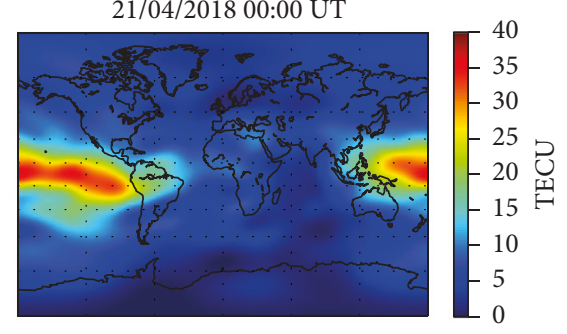

21/04/2018 02:00 UT
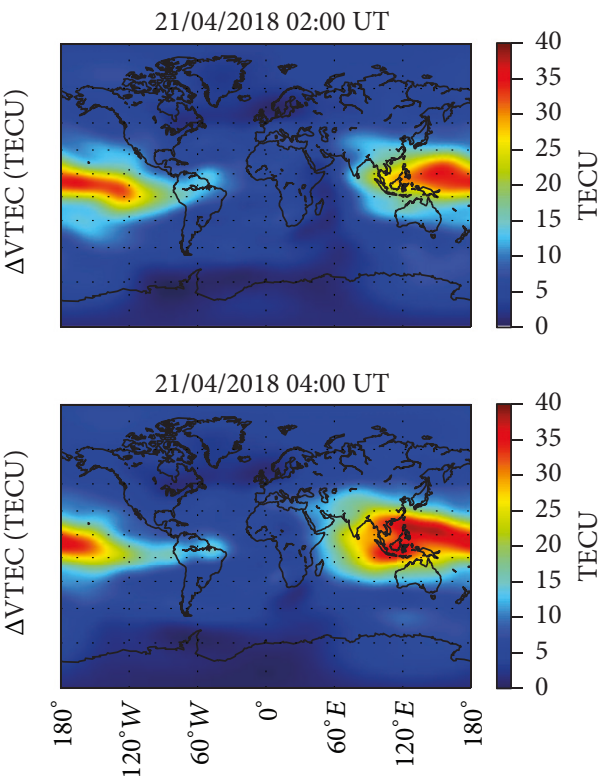

FIGURE 5: Left column: differential VTEC maps between April 20, 2018 (22:00 UT) and April 21, 2018 (04:00 UT). Right column: GIMs between April 20, 2018 (22:00 UT), and April 21, 2018 (04:00 UT).

It is suggested that the super-fountain effect may be playing an important role in the origin of the LTE. Moreover, this LTE is quite unique because, according to a previous study which detected 26 LTEs during 2002-2015, no LTEs have been observed during the solar two-cycle minimum of 2006-2009, and the April 20, 2018, storm occurred during the solar cycle 24 and 25 expected minimum.

Finally, a localized TEC decrement (or negative ionospheric storm) was also identified. This LTD revealed itself in the longitudinal profile of the EIA as the depletion of both its northern and southern crest. The LTD was observed to occur during the recovery phase of the storm. This similar behavior was observed for the 2015 St. Patrick's Day geomagnetic storm. The authors of that study attributed the inhibition of both crests to the westward disturbance dynamo electric field.
Hence, the origin of the LTD during the April 20, 2018, storm is considered to be due to the same mechanism. However, more observations of such types of LTDs are needed in order to understand better their origin.

\section{Data Availability}

The ionospheric data used to support the findings of this study are available from the corresponding author upon request.

\section{Conflicts of Interest}

The author declares that he has no conflicts of interest. 


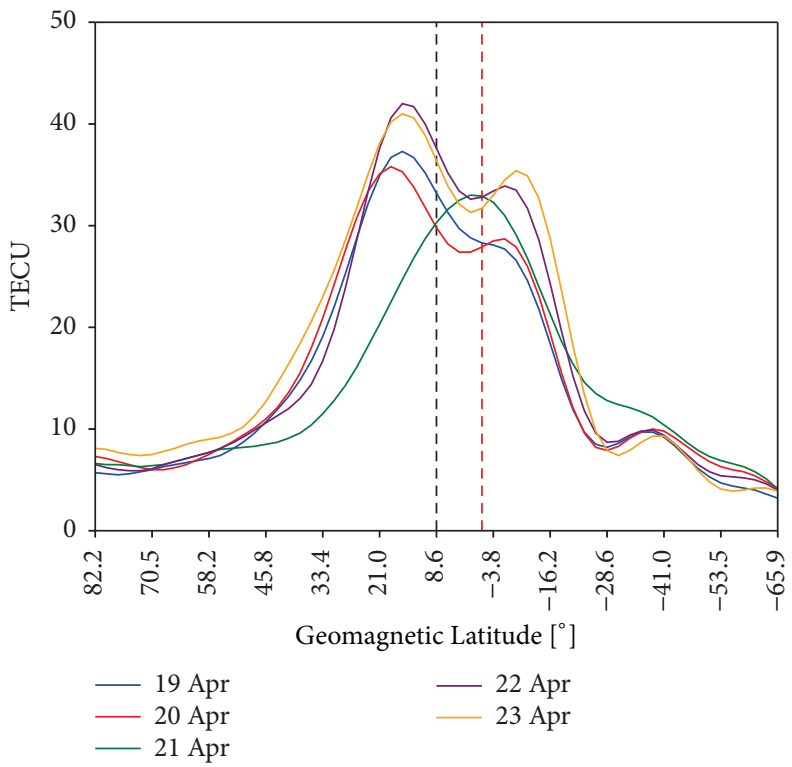

FIgURE 6: Shape of the VTEC for the $100^{\circ} \mathrm{W}$ meridian at 00:00 UT between April 19 and 23, 2018. A relevant range of geomagnetic latitudes is shown, $82.2^{\circ} \mathrm{N}-65.9^{\circ} \mathrm{S}\left(75^{\circ} \mathrm{N}-75^{\circ} \mathrm{S}\right.$ in geographic latitudes). The vertical red and black dashed lines indicate the magnetic equator and the equator (geographic latitude $=0^{\circ}$ ), respectively.

\section{Acknowledgments}

The author would like to acknowledge the Center for Orbit Determination in Europe for making IONEX files available to the public.

\section{References}

[1] J. J. Love and C. A. Finn, "The USGS geomagnetism program and its role in space weather monitoring," Space Weather Journal, vol. 9, no. 7, 2011.

[2] M. H. MacAlester and W. Murtagh, "Extreme space weather impact: An emergency management perspective," Space Weather Journal, vol. 12, no. 8, pp. 530-537, 2014.

[3] I. Tsagouri, A. Belehaki, G. Moraitis, and H. Mavromichalaki, "Positive and negative ionospheric disturbances at middle latitudes during geomagnetic storms," Geophysical Research Letters, vol. 27, no. 21, pp. 3579-3582, 2000.

[4] I. Horvath and B. C. Lovell, "Positive and negative ionospheric storms occurring during the 15 May 2005 geomagnetic superstorm," Journal of Geophysical Research: Space Physics, vol. 120, no. 9, pp. 7822-7837, 2015.

[5] P. R. Fagundes, F. A. Cardoso, B. G. Fejer, K. Venkatesh, B. A. G. Ribeiro, and V. G. Pillat, "Positive and negative GPS-TEC ionospheric storm effects during the extreme space weather event of March 2015 over the Brazilian sector," Journal of Geophysical Research: Space Physics, vol. 121, no. 6, pp. 5613-5625, 2016.

[6] E. V. Appleton, "Two anomalies in the ionosphere [1]," Nature, vol. 157, article 691, 1946.

[7] C. Stolle, C. Manoj, H. Lühr, S. Maus, and P. Alken, "Estimating the daytime Equatorial Ionization Anomaly strength from electric field proxies," Journal of Geophysical Research: Space Physics, vol. 113, no. A9, 2008.

[8] T. Tanaka and K. Ohtaka, "Ionospheric disturbances during low-latitude auroral events and their association with magnetospheric processes," Journal of Geophysical Research: Space
Physics, vol. 101, no. A8, pp. 17151-17159, 1996.

[9] B. Tsurutani, A. Mannucci, B. Iijima et al., "Global dayside ionospheric uplift and enhancement associated with interplanetary electric fields," Journal of Geophysical Research: Space Physics, vol. 109, no. A8, 2004.

[10] C. H. Lin, A. D. Richmond, R. A. Heelis et al., "Theoretical study of the low- and midlatitude ionospheric electron density enhancement during the October 2003 superstorm: Relative importance of the neutral wind and the electric field," Journal of Geophysical Research: Atmospheres, vol. 110, no. A12, 2005.

[11] A. J. Mannucci, B. T. Tsurutani, B. A. Iijima et al., "Dayside global ionospheric response to the major interplanetary events of October 29-30, 2003 'Halloween Storms,' Geophysical Research Letters, vol. 32, no. 12, 2005.

[12] E. Astafyeva, "Effects of strong IMF Bz southward events on the equatorial and mid-latitude ionosphere," Annales Geophysicae, vol. 27, no. 3, pp. 1175-1187, 2009.

[13] C.-S. Huang, J. C. Foster, and M. C. Kelley, "Long-duration penetration of the interplanetary electric field to the lowlatitude ionosphere during the main phase of magnetic storms," Journal of Geophysical Research: Space Physics, vol. 110, no. A11, 2005.

[14] I. Edemskiy, J. Lastovicka, D. Buresova, J. Bosco Habarulema, and I. Nepomnyashchikh, "Unexpected Southern Hemisphere ionospheric response to geomagnetic storm of 15 August 2015," Annales Geophysicae, vol. 36, no. 1, pp. 71-79, 2018.

[15] D. H. Hathaway and L. A. Upton, "Predicting the amplitude and hemispheric asymmetry of solar cycle 25 with surface flux transport," Journal of Geophysical Research: Space Physics, vol. 121, no. 11, pp. 744-753, 2016.

[16] A. Coster and A. Komjathy, "Space weather and the global positioning system," Space Weather Journal, vol. 6, no. 6, 2008.

[17] M. Hernández-Pajares, J. M. Juan, J. Sanz et al., “The IGS VTEC maps: a reliable source of ionospheric information since 1998," Journal of Geodesy, vol. 83, no. 3-4, pp. 263-275, 2009. 
[18] S. Schaer, W. Gurtner, and J. Feltens, "Ionex: The ionosphere map exchange format version 1," 233-247.

[19] T. E. Oliphant, "Python for scientific computing," Computing in Science \& Engineering, vol. 9, no. 3, Article ID 4160250, pp. 1020, 2007.

[20] J. Y. Liu, Y. J. Chuo, S. J. Shan et al., "Pre-earthquake ionospheric anomalies registered by continuous GPS TEC measurements," Annales Geophysicae, vol. 22, no. 5, pp. 1585-1593, 2004.

[21] F. Zhu, Y. Wu, J. Lin, and Y. Zhou, “Temporal and spatial characteristics of VTEC anomalies before Wenchuan Ms8.0 earthquake," Geodesy and Geodynamics, vol. 1, no. 1, pp. 23-28, 2010.

[22] Y. B. Yao, P. Chen, S. Zhang, J. J. Chen, F. Yan, and W. F. Peng, "Analysis of pre-earthquake ionospheric anomalies before the global M $=7.0+$ earthquakes in 2010," Natural Hazards and Earth System Sciences, vol. 12, no. 3, pp. 575-585, 2012.

[23] J. Li, G. Meng, X. You, R. Zhang, H. Shi, and Y. Han, "Ionospheric total electron content disturbance associated with May 12, 2008, Wenchuan earthquake," Geodesy and Geodynamics, vol. 6, no. 2, pp. 126-134, 2015.

[24] M. Sugiura, "Hourly value of equatorial Dst for the IGY," Annals of the International Geophysical Year, vol. 35, 1964.

[25] W. D. Gonzalez, J. A. Joselyn, Y. Kamide et al., "What is a geomagnetic storm?" Journal of Geophysical Research: Atmospheres, vol. 99, no. A4, pp. 5771-5792, 1994.

[26] W. Wang, J. Lei, A. G. Burns et al., "Ionospheric response to the initial phase of geomagnetic storms: Common features," Journal of Geophysical Research: Space Physics, vol. 115, no. A7, 2010.

[27] W. D. Gonzalez and B. T. Tsurutani, "Criteria of interplanetary parameters causing intense magnetic storms (Dst < -100 nT)," Planetary and Space Science, vol. 35, no. 9, pp. 1101-1109, 1987.

[28] B. Zhao, W. Wan, and L. Liu, "Responses of equatorial anomaly to the October-November 2003 superstorms," Annales Geophysicae, vol. 23, no. 3, pp. 693-706, 2005.

[29] E. Astafyeva, I. Zakharenkova, and M. Förster, "Ionospheric response to the 2015 St. Patrick's Day storm: A global multiinstrumental overview," Journal of Geophysical Research: Space Physics, vol. 120, no. 10, pp. 9023-9037, 2015.

[30] L. Spogli, C. Cesaroni, D. Di Mauro et al., "Formation of ionospheric irregularities over Southeast Asia during the 2015 St. Patrick's Day storm," Journal of Geophysical Research: Space Physics, vol. 121, no. 12, pp. 211-233, 2016. 

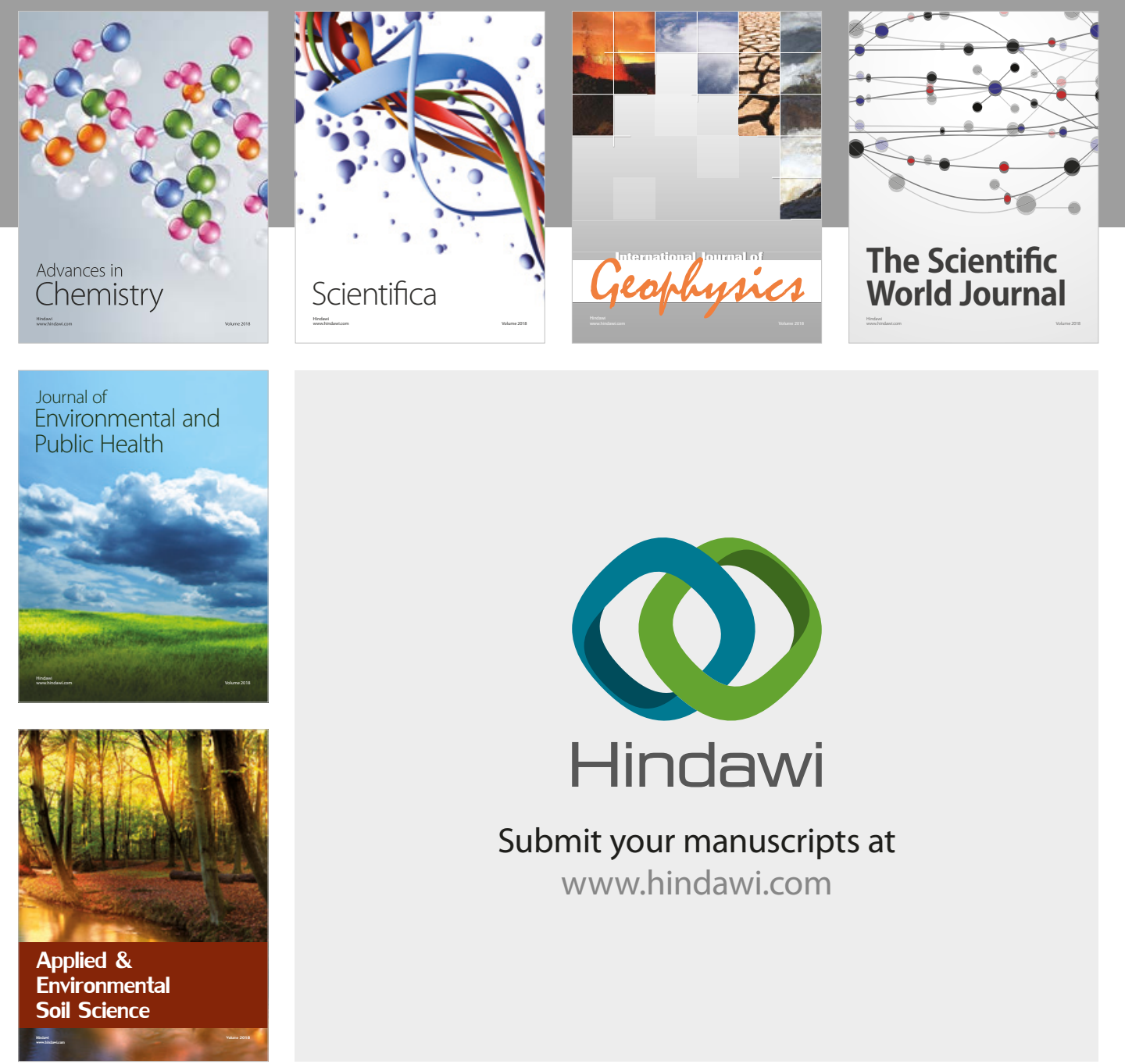

The Scientific

\section{World Journal}
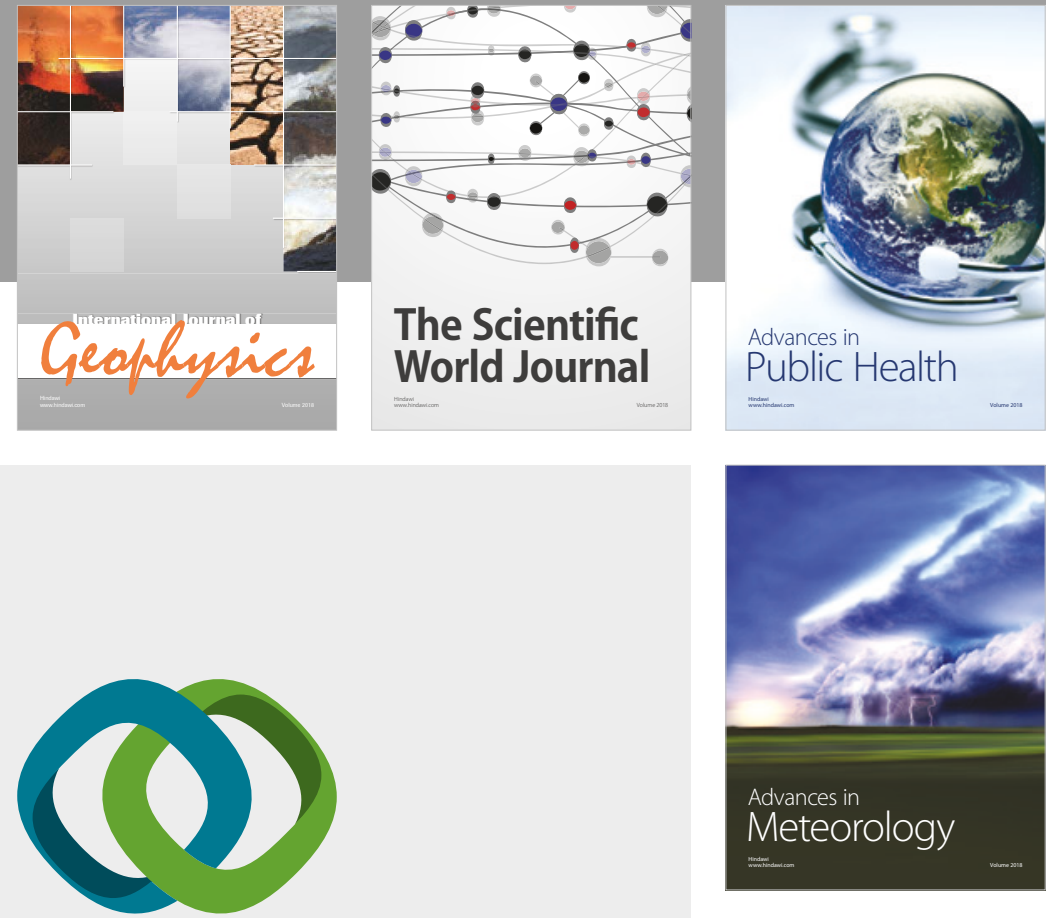

Advan

Public Health

\section{Hindawi}

Submit your manuscripts at

www.hindawi.com
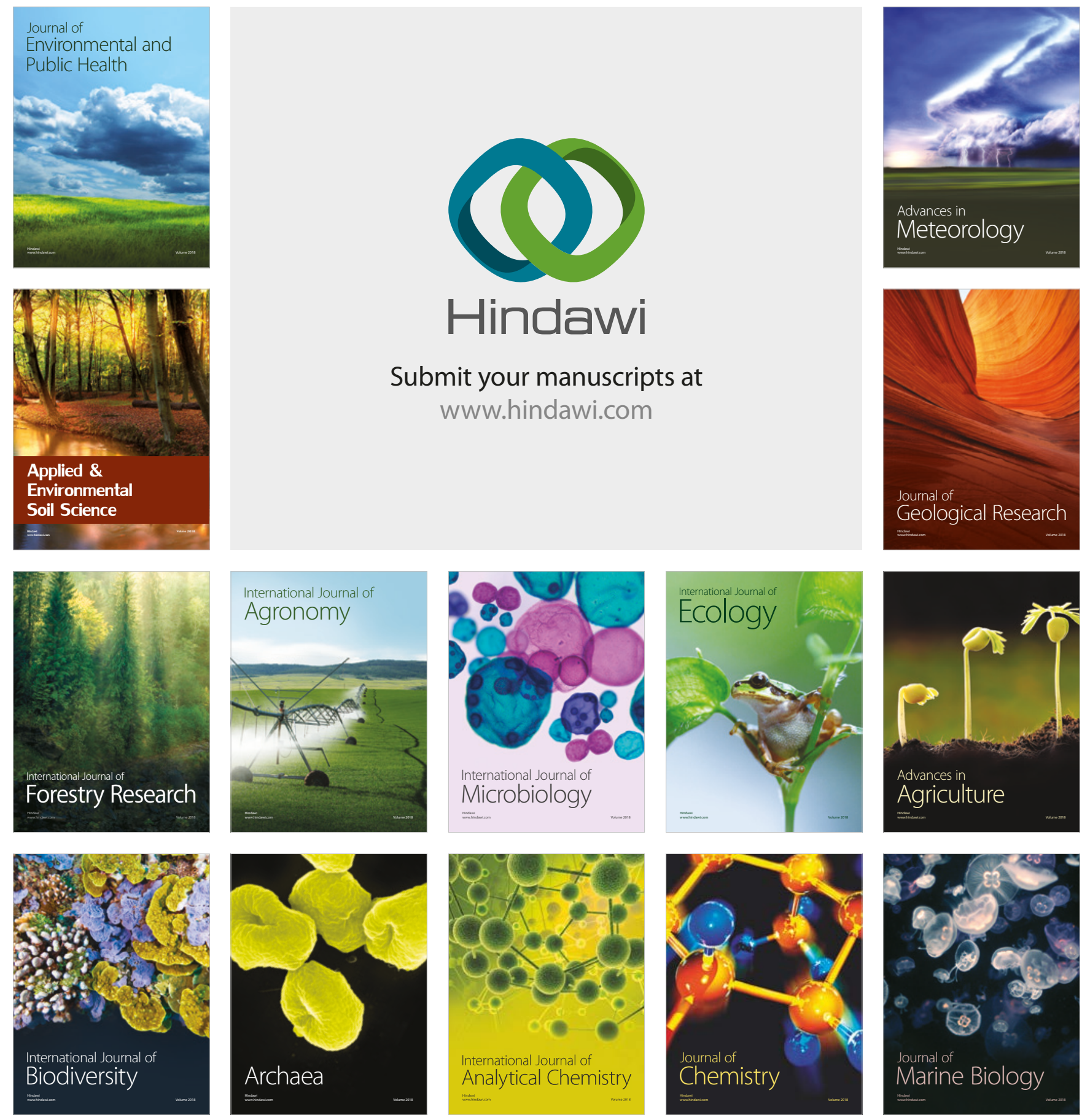